\title{
Age- and gender-specific incidence rates of renal replacement therapy in Japan: an international comparison
}

\author{
Minako Wakasugi ${ }^{1,2 *}$, Junichiro James Kazama ${ }^{3}$ and Ichiei Narita ${ }^{2}$
}

\begin{abstract}
Background: Japan has relatively low incidence rates of renal replacement therapy (RRT) for end-stage kidney disease (ESKD) among those aged 0-19 years, but relatively high rates for the older age band. On the other hand, Australia has relatively high rates among those aged 0-19 years, but relatively low rates for the older age band. Thus, an international comparison between Japan and Australia would be informative. This study aimed to compare age- and gender-specific incidence rates of RRT in Japan with the total incidence of ESKD in Australia, which includes both those who start RRT and those who died of ESKD without RRT, in order to better understand the burden of ESKD independently of differences in the acceptance rate of RRT. We also compared incidence rates in Japan with published data from two major registries, the United States Renal Data System (USRDS) and the European Renal Association-European Dialysis and Transplant Association (ERA-EDTA).

Methods: Data on numbers of patients who initiated RRT in Japan were extracted from data published by the Japanese Society of Dialysis Therapy (JSDT) Registry in 2003-2007 and 2011. Age- and gender-specific incidence rates were calculated by dividing the number of incident patients for each age-gender category by the total number of people in the corresponding population. Incidence in other countries was extracted from a published paper in Australia, tables in the USRDS annual report 2011, and the ERA-EDTA annual report 2011.

Results: Among males aged 50 to 69 years, incidence rates of RRT in Japan were about two times the total incidence of ESKD in Australia. Compared with the incidence rates of RRT reported by the USRDS and the ERA-EDTA, Japanese males have similar or substantially higher rates, respectively.

Conclusions: Japan has a higher incidence of RRT among middle- and older-aged populations compared to the total incidence rates of ESKD in Australia. This higher incidence in Japan cannot be explained by differences in the acceptance rate for RRT since data from Australia included both treated and untreated ESKD. A strategy that targets middle- and older-aged males will be necessary to decrease the incidence of RRT in Japan.
\end{abstract}

Keywords: Clinical epidemiology, Dialysis, Paediatric nephrology, Registries, Renal failure

\section{Background}

The incidence of end-stage kidney disease (ESKD) differs substantially between countries. According to information on ESKD provided by the United States Renal Data System (USRDS) using data from 42 regions and countries,

\footnotetext{
*Correspondence: minakowa@med.niigata-u.ac.jp

'Division of Comprehensive Geriatrics in Community, Niigata University Graduate School of Medical and Dental Science, 1-757 Asahimachi, Chuo-ku, Niigata 951-8510, Japan

${ }^{2}$ Division of Clinical Nephrology and Rheumatology, Niigata University Graduate School of Medical and Dental Science, 1-757 Asahimachi, Chuo-ku, Niigata 951-8510, Japan

Full list of author information is available at the end of the article
}

unadjusted incidence rates of reported ESKD in 2011 were 527 per million population in Jalisco (Mexico), followed by 362 in the USA, 361 in Taiwan (2010), and 295 in Japan [1]. However, these rates were not adjusted by age and gender. Since the risk of ESKD differs by age and gender, population demographics would affect the rates.

When considered by age band, some countries have incidence rates of ESKD which are high in some age bands and low in others [2]. Japan has relatively low incidence rates of reported ESKD among those aged 019 years, but relatively high rates for the older age band. On the other hand, Australia has relatively high incidence 
rates of reported ESKD among those aged 0-19 years, but relatively low rates for the older age band [2]. These findings suggest that an international comparison of age- and gender-specific incidence rates between Japan and Australia would be informative and drive further research.

Recently, the total incidence of ESKD in Australia, which includes both those who start renal replacement therapy (RRT) and those who die of ESKD without RRT, has been estimated [3]. Unfortunately, no data are available on the total incidence of adult ESKD in Japan. However, it would be more informative to compare the incidence of RRT in Japan with the total incidence of ESKD in Australia, rather than the reported incidence rates of ESKD (which include only those who start RRT), in order to better understand the burden of ESKD independently of differences in the acceptance rate of RRT.

This study aimed to compare age- and gender-specific incidence rates of RRT in Japan with the total incidence of ESKD in Australia. We also compared incidence rates in Japan with published data from two major registries, the USRDS and the European Renal Association-European Dialysis and Transplant Association (ERA-EDTA).

\section{Methods}

\section{Data source}

Data on numbers of patients who initiated RRT in Japan were extracted from data published by the Japanese Society of Dialysis Therapy (JSDT) Registry in 2003-2007 [4-8] and 2011 [9]. Data collection methods of the JSDT Registry have been described elsewhere [9]. In brief, the JSDT Registry collects annual data by sending questionnaires to all dialysis facilities in Japan. Response rates were $99.12 \%$ in 2003 [4], $98.73 \%$ in 2004 [5], $98.87 \%$ in 2005 [6], $98.37 \%$ in 2006 [7], $98.88 \%$ in 2007 [8], and $99.0 \%$ in 2011 [9]. It is important to note that only patients who underwent dialysis treatment were included in the JSDT Registry, as data were unavailable for adult patients who did not initiate dialysis or who received a preemptive kidney transplant. Although the number of preemptive kidney transplant patients is still small among the adult Japanese population [10], there has been a marked increase in the use of preemptive kidney transplantation as the initial treatment modality for paediatric RRT [11]. Thus, we also extracted data on incident paediatric ESKD patients in Japan from survey data published by the Japanese Society for Paediatric Nephropathy (JSPN) in 2006-2011 [11], which included patients who did not initiate RRT or who received preemptive kidney transplants.

Population data in 2003-2007 and 2011 were extracted from the national census $[12,13]$. Data on ageand gender-specific total incidence of ESKD in Australia were extracted from a published paper [3]. We also extracted data on the age-specific incidence of reported ESKD from tables in the 2011 USRDS annual report [14] and the 2011 ERA-EDTA annual report [15].

\section{Data analyses}

Age- and gender-specific incidence rates were calculated by dividing the number of incident patients for each agegender category by the total number of people in the corresponding population. For comparisons with total incidence rates of ESKD in Australia between 2003 and 2007, we calculated the incidence of RRT using data from the JRDR during the same time period. We also calculated the total incidence of paediatric ESKD using data from the JSPN [11]. Standardised incidence ratios (SIRs) were calculated by the indirect method, using age- and genderspecific total incidence rates for Australia as the reference category. Confidence intervals were determined assuming that observed cases followed a Poisson distribution.

To compare incidence rates of the USRDS and the ERA-EDTA, we calculated the incidence of RRT using data from the JRDR in 2011. The incidence of RRT at day 1 in the ERA-EDTA was used for this analysis. We also compared the total incidence of paediatric ESKD using data from the JSPN [11] for those aged $<20$ years with the incidence of RRT reported by the USRDS and the ERA-EDTA (Additional files 1, 2, and 3).

The current analyses used existing data without any individual patient identifiers. The study was performed according to the principles of the 2000 Declaration of Helsinki as well as the Declaration of Istanbul 2008, Japanese privacy protection laws, and ethical guidelines for epidemiological studies published by the Ministry of Education, Science and Culture, and the Ministry of Health, Labour and Welfare in 2005.

\section{Results and discussion}

\section{Age-specific incidence rates of RRT in Japan}

There were 110,475 male and 62,217 female incident cases of RRT in 2003-2007 in Japan. Unadjusted overall incidence rates were 358.8 per million population (pmp) (95\% confidence interval (CI), 356.7-360.9) for males and $192.7 \mathrm{pmp}$ (95 \% CI, 191.2-194.2) for females (Table 1). Age-specific incidence rates increased with age, peaking between ages 80 and 84 years in both genders. The rates were higher in males than in females; however, this gender difference was not apparent among those aged $<15$ years.

Using data from the JSPN [11], there were no gender differences in the total incidence of paediatric ESKD among children aged $<10$ years (Additional file 1). Age-specific total incidence rates of paediatric ESKD were higher than the incidence rates of RRT shown in Table 1 for all age groups, except among those aged 15-19 years. 
Table 1 Incidence of end-stage kidney disease treated by dialysis in Japan, 2003-2007

\begin{tabular}{|c|c|c|c|c|c|c|}
\hline \multirow{2}{*}{$\begin{array}{l}\text { Age group } \\
\text { (years) }\end{array}$} & \multicolumn{3}{|l|}{ Males } & \multicolumn{3}{|l|}{ Females } \\
\hline & Incident case & Population $^{a}$ & Incidence $^{\mathrm{b}}$ (95\% Cl) & Incident case & Population $^{\text {a }}$ & Incidence ${ }^{\mathrm{b}}(95 \% \mathrm{Cl})$ \\
\hline $0-4$ & 43 & $14,249,165$ & $3.0(2.2-4.1)$ & 37 & $13,551,230$ & $2.7(1.9-3.8)$ \\
\hline $5-9$ & 26 & $15,075,316$ & $1.7(1.1-2.5)$ & 18 & $14,344,246$ & $1.3(0.7-2.0)$ \\
\hline $10-14$ & 41 & $15,361,059$ & $2.7(1.9-3.6)$ & 38 & $14,614,548$ & $2.6(1.8-3.6)$ \\
\hline $15-19$ & 128 & $16,778,802$ & $7.6(6.4-9.1)$ & 81 & $15,900,857$ & $5.1(4.0-6.3)$ \\
\hline $20-24$ & 355 & $18,747,907$ & $18.9(17.0-21.0)$ & 180 & $17,744,081$ & $10.1(8.7-11.7)$ \\
\hline $25-29$ & 681 & $20,839,834$ & $32.7(30.3-35.2)$ & 406 & $20,057,000$ & $20.2(18.3-22.3)$ \\
\hline $30-34$ & 1385 & $23,994,021$ & $57.7(54.7-60.8)$ & 724 & $23,324,334$ & $31.0(28.8-33.4)$ \\
\hline $35-39$ & 2176 & $22,100,968$ & $98.5(94.4-102.7)$ & 1047 & $21,607,875$ & $48.5(45.6-51.5)$ \\
\hline $40-44$ & 3037 & $19,854,793$ & $153.0(147.6-158.5)$ & 1449 & $19,519,867$ & $74.2(70.5-78.2)$ \\
\hline $45-49$ & 4734 & $19,295,649$ & $245.3(234.8-252.4)$ & 2238 & $19,150,550$ & $116.9(112.1-121.8)$ \\
\hline $50-54$ & 8350 & $22,042,543$ & $378.8(370.7-387.0)$ & 3961 & $22,159,275$ & $178.8(173.2-184.4)$ \\
\hline $55-59$ & 12,972 & $24,739,582$ & $524.3(515.4-533.4)$ & 5644 & $25,291,277$ & $223.2(217.4-229.1)$ \\
\hline $60-64$ & 13,990 & $20,366,525$ & $686.9(675.6-698.4)$ & 6617 & $21,542,247$ & $307.2(299.8-314.7)$ \\
\hline $65-69$ & 16,000 & $17,861,105$ & 895.8 (882.0-909.8) & 8213 & $19,630,862$ & $418.4(409.4-427.5)$ \\
\hline $70-74$ & 17,680 & $15,166,918$ & 1165.7 (1148.6-1183.0) & 9341 & $17,928,932$ & $521.0(510.5-531.7)$ \\
\hline $75-79$ & 15,252 & $11,193,826$ & $1362.5(1341.0-1384.3)$ & 9867 & $14,967,274$ & $659.2(646.3-672.4)$ \\
\hline $80-84$ & 9119 & $6,180,288$ & 1475.5 (1445.4-1506.1) & 7591 & $10,954,849$ & $692.9(677.4-708.7)$ \\
\hline$\geq 85$ & 4506 & $4,061,592$ & $1109.4(1077.3-1142.3)$ & 4765 & $10,559,705$ & $451.2(438.5-464.2)$ \\
\hline Total & 110,475 & $307,909,893$ & $358.8(356.7-360.9)$ & 62,217 & $322,849,009$ & $192.7(191.2-194.2)$ \\
\hline
\end{tabular}

Only patients who initiated dialysis treatment were included

$\mathrm{Cl}$ confidence interval

${ }^{\text {a }}$ Five-year population at risk

${ }^{\mathrm{b}}$ Per million age-related population (pmarp)

\section{Comparison with other countries}

Table 2 shows SIRs of the incidence of RRT in Japan in comparison with the total incidence of ESKD in Australia in 2003-2007. Overall SIRs were 1.19 (95\% CI, 1.18-1.20) for males and 0.68 (95\% CI, 0.68-0.69) for females. For males, Japan had lower SIRs at age $<30$ years, higher SIRs in age band $30-79$, and then lower SIRs at age $\geq 80$ years. Among males aged 50 to 69 years, incidence rates of RRT in Japan were about twice as high as the total incidence of ESKD among males in Australia. For females, Japan had lower SIRs at age $<35$ years, higher SIRs in age band 4074 , and then lower SIRs at age $\geq 75$ years. Among females aged 50 to 69 years, incidence rates of RRT in Japan were about one and a half times higher than the total incidence of ESKD among females in Australia.

When comparing the total incidence of paediatric ESKD in Japan and Australia, Japan had lower SIRs at all age groups except the female group aged 0-4 years and the male group aged 10-14 years (Additional file 2).

Figure 1 shows age- and gender-specific incidence rates of adult RRT in Japan in comparison with those of the USRDS. The incidence increased with age, peaking between ages 80 and 84 years in both countries, with similar rates observed between Japanese males and the
USRDS. Japanese males have also substantially higher rates compared with the ERA-EDTA (Fig. 2). Figure 3 shows the age- and gender-specific paediatric incidence of RRT reported by the USRDS, the ERA-EDTA, and the JRDR. Japan has lower incidence rates compared with those reported by the USRDS and the ERA-EDTA. Similar results were obtained using data from the JSPN (Additional file 3).

\section{Discussion}

This study revealed that the incidence of RRT in middleaged individuals in Japan was almost twice the total incidence of ESKD in Australia. Since data from Australia included both treated and untreated ESKD [3], the higher incidence in Japan cannot be explained by differences in the acceptance rate for RRT. Furthermore, compared with the incidence rates of RRT reported by the USRDS and the ERA-EDTA, Japanese males have similar or substantially higher rates, respectively. These findings suggest that there still is room for substantially decreasing gender- and age-specific incidence rates of ESKD in these populations.

The most striking finding of this study was that the incidence of RRT in middle-aged individuals in Japan was 
Table 2 SIR of ESKD in Japan compared with the total incidence of ESKD in Australia

\begin{tabular}{|c|c|c|c|c|c|c|}
\hline \multirow{2}{*}{$\begin{array}{l}\text { Age group } \\
\text { (years) }\end{array}$} & \multicolumn{3}{|l|}{ Males } & \multicolumn{3}{|l|}{ Females } \\
\hline & Incidence $(95 \% \mathrm{Cl})^{\mathrm{a}}$ & Expected cases & SIR $(95 \% \mathrm{Cl})$ & Incidence $(95 \% \mathrm{Cl})^{\mathrm{a}}$ & Expected cases & SIR $(95 \%$ CI) \\
\hline $0-4$ & $0.8(0.5-1.1)$ & 114 & $0.38(0.27-0.51)$ & $0.3(0.2-0.6)$ & 41 & $0.91(0.64-1.24)$ \\
\hline $5-9$ & $0.8(0.5-1.1)$ & 121 & $0.22(0.14-0.32)$ & $0.6(0.4-1.0)$ & 86 & $0.21(0.12-0.33)$ \\
\hline $10-14$ & $0.5(0.3-0.8)$ & 77 & $0.53(0.38-0.72)$ & $0.8(0.5-1.1)$ & 117 & $0.33(0.23-0.45)$ \\
\hline $15-19$ & $1.6(1.3-2.1)$ & 268 & $0.48(0.40-0.57)$ & $1.3(1.0-1.7)$ & 207 & $0.39(0.31-0.49)$ \\
\hline $20-24$ & $2.7(2.2-3.3)$ & 506 & $0.70(0.63-0.78)$ & $1.8(1.4-2.3)$ & 319 & $0.56(0.49-0.65)$ \\
\hline $25-29$ & $4.0(3.4-4.7)$ & 834 & $0.82(0.76-0.88)$ & $3.0(2.5-3.6)$ & 602 & $0.67(0.61-0.74)$ \\
\hline $30-34$ & $4.8(4.1-5.6)$ & 1152 & $1.20(1.14-1.27)$ & $4.0(3.4-4.7)$ & 933 & $0.78(0.72-0.84)$ \\
\hline $35-39$ & $7.4(6.5-8.3)$ & 1635 & $1.33(1.28-1.39)$ & $5.0(4.3-5.7)$ & 1080 & $0.97(0.91-1.03)$ \\
\hline $40-44$ & $10.4(9.4-11.5)$ & 2065 & $1.47(1.42-1.52)$ & $6.8(6.0-7.7)$ & 1327 & $1.09(1.04-1.15)$ \\
\hline $45-49$ & 13.7 (12.5-15.0) & 2644 & $1.79(1.74-1.84)$ & $8.7(7.9-9.8)$ & 1666 & $1.34(1.29-1.40)$ \\
\hline $50-54$ & $18.5(17.0-20.1)$ & 4078 & $2.05(2.00-2.09)$ & $10.8(9.7-12.0)$ & 2393 & $1.66(1.60-1.71)$ \\
\hline $55-59$ & 23.6 (21.9-25.5) & 5839 & $2.22(2.18-2.26)$ & $16.3(14.8-17.8)$ & 4122 & $1.37(1.33-1.41)$ \\
\hline $60-64$ & $32.1(29.8-34.7)$ & 6538 & $2.14(2.10-2.18)$ & $21.2(19.4-23.3)$ & 4567 & $1.45(1.41-1.48)$ \\
\hline $65-69$ & $49.8(46.4-53.4)$ & 8895 & $1.80(1.77-1.83)$ & 33.7 (31.1-36.6) & 6616 & $1.24(1.22-1.27)$ \\
\hline $70-74$ & 80.6 (75.8-85.8) & 12,225 & $1.45(1.43-4.70)$ & $50.1(46.6-53.9)$ & 8982 & $1.04(1.02-1.06)$ \\
\hline $75-79$ & 127.5 (120.6-134.9) & 14,272 & $1.07(1.05-1.09)$ & 75.8 (71.1-80.8) & 11,345 & $0.87(0.85-0.89)$ \\
\hline $80-84$ & $216.1(204.7-228.1)$ & 13,356 & $0.68(0.67-0.70)$ & 117.5 (110.8-124.7) & 12,872 & $0.59(0.58-0.60)$ \\
\hline$\geq 85$ & $447.3(524.7-570.0)$ & 18,168 & $0.25(0.24-0.26)$ & 318.7 (305.3-332.8) & 33,654 & $0.14(0.14-0.15)$ \\
\hline Total & $26.1(22.5-30.0)$ & 92,784 & $1.19(1.18-1.20)$ & $17.0(14.9-19.2)$ & 90,930 & $0.68(0.68-0.69)$ \\
\hline
\end{tabular}

Reproduced from [3]

$\mathrm{Cl}$ confidence interval, ESKD end-stage kidney disease, SIR standardised incidence ratio

aper 100,000 population

almost twice the total incidence of ESKD in Australia. Although no data are available on the precise number of untreated ESKD patients in Japan, the total incidence of ESKD in Japan, including both treated and untreated patients, would be over twofold that reported in Australia.
Primary renal disease in new patients was similar between Australia and Japan. Specifically, diabetic nephropathy was the most common cause of ESKD followed by glomerulonephritis in both countries, although the proportions were slightly different. Diabetic nephropathy

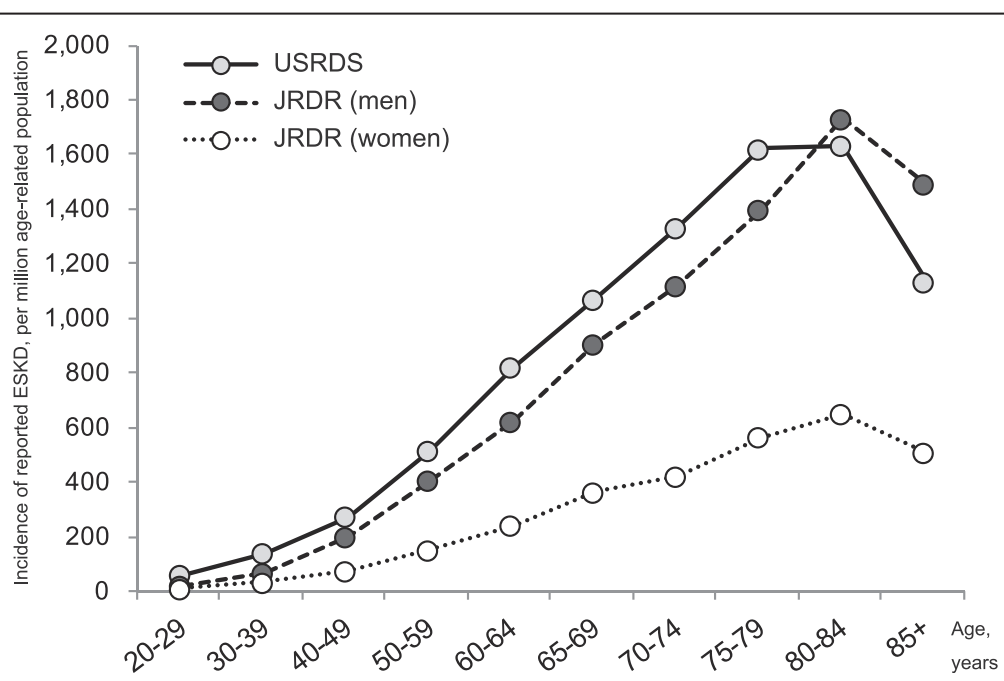

Fig. 1 Age- and gender-specific adult incidence rates of reported ESKD in Japan compared with the USRDS. Note: Data from the Japanese Society of Dialysis Therapy registry (JRDR) include data only for patients who underwent dialysis treatment 


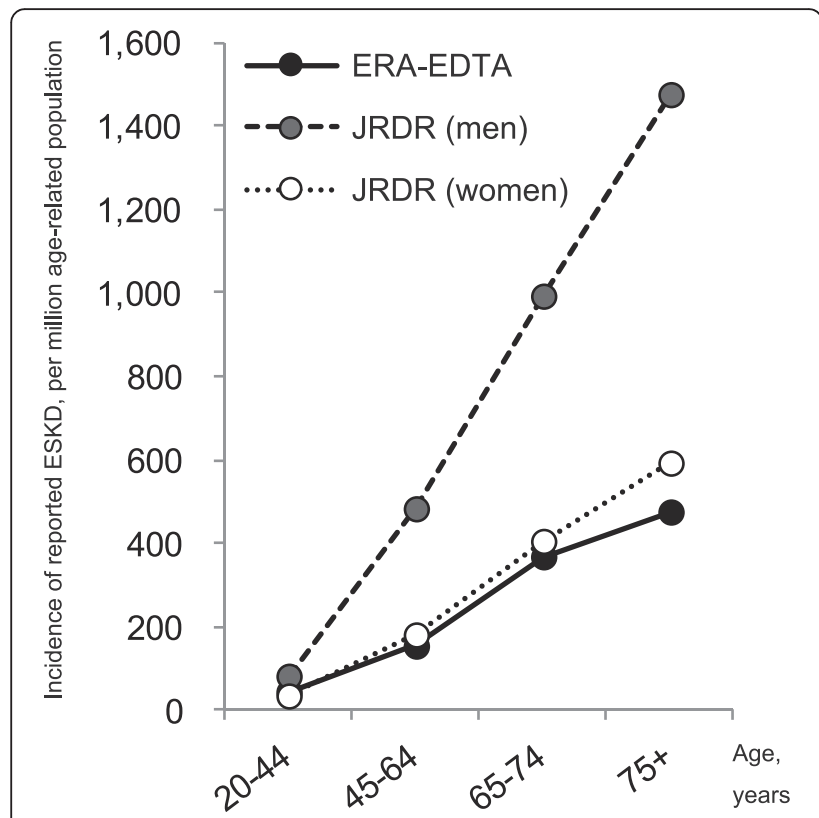

Fig. 2 Age- and gender-specific adult incidence rates of reported ESKD in Japan compared with the ERA-EDTA. Note: Data from the Japanese Society of Dialysis Therapy registry (JRDR) include data only for patients who underwent dialysis treatment

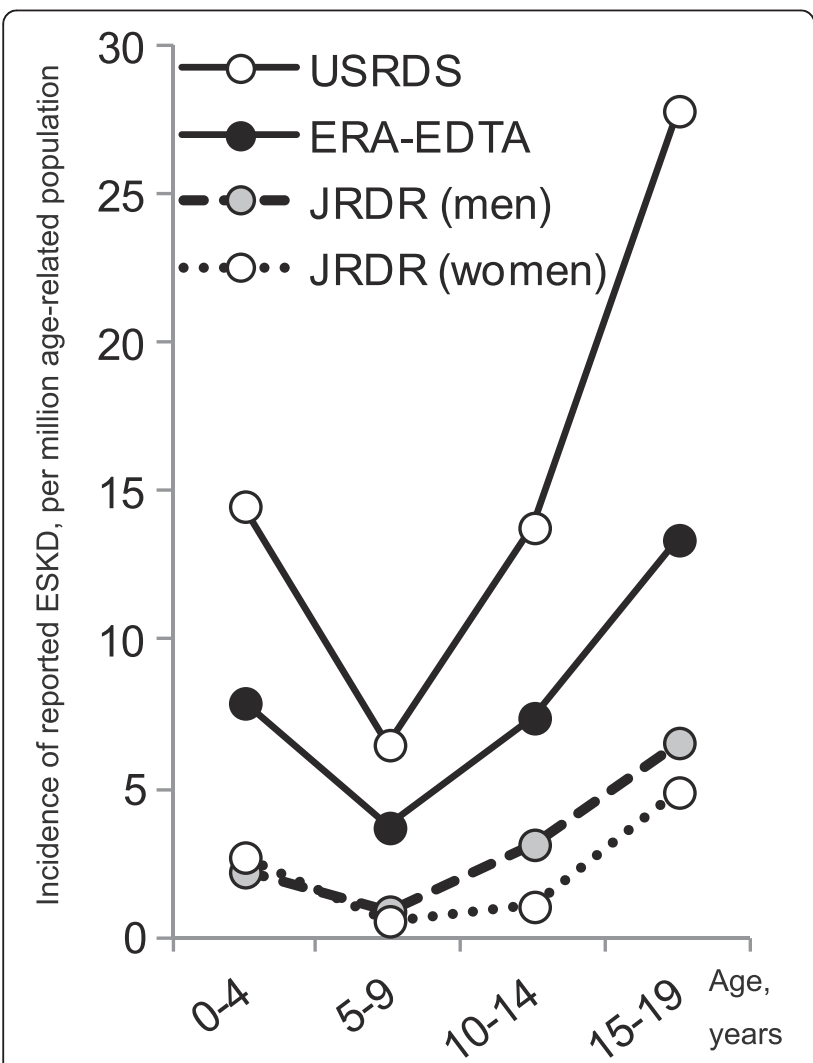

Fig. 3 Paediatric incidence rates of reported ESKD in Japan compared with the USRDS and the ERA-EDTA. Note: Data from the Japanese Society of Dialysis Therapy registry (JRDR) include data only for patients who underwent dialysis treatment accounted for $26 \%$ of new patients in Australia and $41.0 \%$ in Japan, respectively, in 2003, 30 and $41.0 \%$ in 2004, 31 and $40.7 \%$ in 2005, 32 and $36.6 \%$ in 2006, and 31 and $43.5 \%$ in 2007 [4-8, 16, 17]. Glomerulonephritis and chronic glomerulonephritis were the second leading cause in Australia and Japan, respectively. In Australia, glomerulonephritis accounted for $27 \%$ of new patients in $2003,25 \%$ in 2004, $24 \%$ in 2005, $23 \%$ in 2006, and $25 \%$ in 2007 [16, 17]. In Japan, chronic glomerulonephritis accounted for $29.1 \%$ in 2003, $28.1 \%$ in $2004,30.8 \%$ in 2005, $23.7 \%$ in 2006, and $23.8 \%$ in 2007 [4-8]. Due to differences in categories of underlying diseases by different registries, direct comparisons may not be possible. Furthermore, age- and sex-stratified data of primary renal disease are lacking. Given substantial differences in primary renal diseases by age, this is an important area that requires further research.

The timing of dialysis initiation was also similar between Australia and Japan. The median estimated glomerular filtration rate (eGFR) at RRT initiation in Australia was around 6 to $7 \mathrm{~mL} / \mathrm{min} / 1.73 \mathrm{~m}^{2}$ between 2004 and 2007 [18]. On the other hand, the mean eGFR at dialysis initiation in Japan was $6.52 \mathrm{~mL} / \mathrm{min} / 1.73 \mathrm{~m}^{2}$ in 2007 [19]. Thus, it is unlikely that Japanese patients begin dialysis at a higher eGFR than patients in Australia.

One possibility is that the estimated total incidence of ESKD in Australia is underestimated. Indeed, a recent report regarding the quality of coding of ESKD in Australian death records suggests that death records significantly underestimate the impact of ESKD [20]. Thus, those who die of ESKD without RRT in Australia may be underestimated, and the acceptance rate of RRT in Australia may be lower than the estimated rate. Notwithstanding, the twofold increase in rates appears too large to be entirely explained by the acceptance rate of RRT.

We cannot provide a conclusive explanation as to why Japan has higher incidence rates of RRT; however, racial differences may also play a role. A prospective cohort study from the UK revealed that Indo-Asian people had a higher incidence of ESKD than their Caucasian counterparts [21]. Another cohort study from the Netherlands revealed that South-Asian patients with type 2 diabetes, which is now the most common single cause of ESKD in Japan, had a higher incidence and faster progression of renal dysfunction compared with Dutch-European diabetic patients [22]. These studies suggest that the kidneys of Asians may be more vulnerable than those of other ethnic groups.

The prevalence of chronic kidney disease (CKD) stages 3 and 4 in Japan is similar to that in the USA although the general Japanese population seems to adopt a healthier lifestyle, further supporting the notion that the kidneys of Japanese people are more vulnerable. For example, the distribution of healthy lifestyle scores, which reflects 
adherence to five lifestyle factors (non-smoking, optimal weight, moderate alcohol intake, regular physical activity, and better eating patterns), was as follows among females aged 34 to 59 years in the USA [23] and the general Japanese population aged 40 to 74 years [24]: 4.2 and $0.5 \%$, respectively, had a score of 0 (least healthy); 21 and $5.2 \%$ had a score of $1 ; 34$ and $17.5 \%$ had a score of $2 ; 27$ and $31.3 \%$ had a score of 3; 12 and $32.3 \%$ had a score of 4; and 2.4 and $13.3 \%$ had a score of 5 (most healthy), although the definition of a healthy lifestyle slightly differed between the studies. Nevertheless, the prevalence of CKD stages 3 and 4 in Japan is similar to that in the USA $[25,26]$. Furthermore, the prevalence of proteinuria in Japan is reportedly much higher than that in the USA [27]. While these all support the notion that incidence rates of ESKD can be attributed to racial differences, factors other than race may also affect the rates, since age-specific incidence rates of ESKD differ substantially between the USRDS, the ERA-EDTA, and Australia. Gathering and analysing more information on these international differences will provide better insight and help decrease the incidence of ESKD. To allow for international comparisons in the future, data for all ESKD registries should be reported in the same manner.

This study also revealed that the incidence of RRT in men is higher than that in women in Japan. The reason underlying this difference is unclear, as evidence for sex differences in the incidence of RRT is scarce. Although there are no apparent differences in the prevalence of CKD stages 3-5 between Japanese men and women, the prevalence of proteinuria, hypertension, and diabetes in men are all higher than in women in the general Japanese population [26], suggesting that men might be more likely to progress to ESKD than women. Although access to dialysis or patient/doctor preferences may also contribute to these differences, no such data are available in Japan. Thus, the reasons underlying the sex differences should be addressed in future studies.

With respect to the young population, Japan has a lower incidence of paediatric ESKD compared to the incidence of ESKD reported by the USRDS and the ERAEDTA. Compared with the total incidence of ESKD in Australia, Japan had lower SIRs in all age groups, except the female group aged 0-4 years and the male group aged 10-14 years. Although data available in the present study do not provide sufficient information regarding why Japan has such lower incidence rates of paediatric ESKD, there are several potential explanations. First, universal screening with the urine dip-stick test, which was introduced as an annual urinalysis screening programme for every school child since 1973 in Japan, may have been effective in preventing ESKD in children, whereas no global consensus exists on whether screening for CKD should be undertaken in children and adolescents and whether such screening is cost effective [28]. Although direct evidence is lacking, early referral and intervention for glomerulonephritis identified by the screening programme may have reduced the incidence of childhood ESKD in Japan [27]. Second, the incidence rates of paediatric ESKD might be underestimated, particularly in the group aged 15-19 years. The total incidence rates of paediatric ESKD, which included patients who did not initiate RRT or who received preemptive kidney transplants, were lower than the rates of RRT in the group aged 15-19 years, suggesting that the number of paediatric ESKD patients may be much higher than reported.

Despite the fact that Japan has one of the highest incidence rates of ESKD among adults, it was previously reported to be much lower than that in other high-income countries [29]. Our findings, however, suggest that it may premature to conclude that Japan has a lower incidence of paediatric ESKD compared to other countries without a more accurate survey of paediatric ESKD patients in Japan.

One strength of this study is that data were extracted from a nationwide survey of Japanese dialysis facilities and a national census. Thus, the findings should be broadly generalisable to the Japanese population. Enhanced awareness of these issues would enable nephrologists and healthcare professionals to advocate for the need to prevent the development and progression of CKD. However, our findings should be interpreted in the context of the limitation inherent to this type of study, i.e. only patients who underwent dialysis treatment were included, as data were unavailable for patients who did not initiate dialysis or who underwent preemptive kidney transplantation in Japan. However, the number of preemptive kidney transplant patients is small in Japan, with only 101 patients being reported in 2009 [10]. In addition, each registry uses different methods to collect and report data. This could have introduced bias. Furthermore, age- and sex-stratified data of comorbidities or primary renal disease are limited due to the data source. Given that these differ substantially by age and sex, this is an important area that requires further research.

\section{Conclusions}

Japan has a higher incidence of RRT among the middleaged and older-aged populations compared to the total incidence rates of ESKD in Australia. Since data from Australia included both treated and untreated ESKD [3], the higher incidence in Japan cannot be explained by differences in the acceptance rate for RRT. Thus, a strategy targeting middle- and older-aged groups will be necessary to decrease the incidence of ESKD in Japan. 


\section{Additional files}

\section{Additional file 1: Total incidence of paediatric end-stage kidney disease in Japan, 2006-2011. (DOC $33 \mathrm{~kb}$ ) \\ Additional file 2: Standardised incidence ratio of the total incidence of paediatric end-stage kidney disease in Japan compared with Australia. (DOC $33 \mathrm{~kb}$ ) \\ Additional file 3: Age- and gender-specific paediatric incidence rates of reported ESKD (per million age-related population) in Japan compared with the USRDS and the ERA-EDTA. (DOC $45 \mathrm{~kb}$ )}

\section{Abbreviations}

Cl: confidence interval; CKD: chronic kidney disease; ERA-EDTA: European Renal Association-European Dialysis and Transplant Association; ESKD: endstage kidney disease; JSDT: Japanese Society of Dialysis Therapy; JSPN: Japanese Society for Paediatric Nephropathy; RRT: renal replacement therapy; SIR: standardised incidence ratio; USRDS: United States Renal Data System.

\section{Competing interests}

The authors declare that they have no competing interests.

\section{Authors' contributions}

MW conceived the study, participated in its design, performed the statistical analysis, and drafted the manuscript. JJK and IN participated in the design of the study and coordination and helped draft the manuscript. All authors read and approved the final manuscript.

\section{Acknowledgements}

This study was supported in part by a Grant-in-Aid for Research on Advanced Chronic Kidney Disease, Practical Research Project for Renal Diseases from Japan Agency for Medical Research and development, AMED. No funding agency had any role in the study design; collection, analysis, and interpretation of data; writing the report; and the decision to submit the report for publication. The data reported here have been provided by the Japanese Society for Dialysis Therapy (JSDT). The interpretation and reporting of these data are the responsibility of the authors and in no way should be seen as an official policy or interpretation of the JSDT.

\section{Author details}

${ }^{1}$ Division of Comprehensive Geriatrics in Community, Niigata University Graduate School of Medical and Dental Science, 1-757 Asahimachi, Chuo-ku, Niigata 951-8510, Japan. '2Division of Clinical Nephrology and Rheumatology, Niigata University Graduate School of Medical and Dental Science, 1-757 Asahimachi, Chuo-ku, Niigata 951-8510, Japan. ${ }^{3}$ Division of Blood Purification Therapy, Niigata University Medical and Dental Hospital, 1-757 Asahimachi, Chuo-ku, Niigata 951-8510, Japan.

Received: 4 September 2015 Accepted: 18 October 2015 Published online: 18 February 2016

\section{References}

1. U.S. Renal Data System. USRDS 2013 annual data report: atlas of CKD and ESRD. Volume 2 - Atlas ESRD, 12 - International comparisons. http://www. usrds.org/2013/pdf/v2_ch12 13.pdf. 2013. Accessed 29 May 2014.

2. Caskey F, Steenkamp R, Ansell D. International comparison of UK registry data (chapter 17). Nephrol Dial Transplant. 2007:22 Suppl 7:vii185-93.

3. Sparke C, Moon L, Green F, Mathew T, Cass A, Chadban S, et al. Estimating the total incidence of kidney failure in Australia including individuals who are not treated by dialysis or transplantation. Am J Kidney Dis. 2013;61:413-9.

4. Patient Registration Committee, Japanese Society for Dialysis Therapy, Tokyo, Japan. An overview of regular dialysis treatment in Japan as of 31 December 2003. Ther Apher Dial. 2005;9:431-58.

5. Nakai S, Wada A, Kitaoka T, Shinzato T, Nagura Y, Kikuchi K, et al. An overview of regular dialysis treatment in Japan (as of 31 December 2004). Ther Apher Dial. 2006:10:476-97.

6. Nakai S, Masakane I, Akiba T, Iseki K, Watanabe Y, Itami N, et al. Overview of regular dialysis treatment in Japan (as of 31 December 2005). Ther Apher Dial. 2007;11:411-41.
7. Nakai S, Masakane I, Akiba T, Shigematsu T, Yamagata K, Watanabe Y, et al. Overview of regular dialysis treatment in Japan as of 31 December 2006. Ther Apher Dial. 2008;12:428-56.

8. Nakai S, Masakane I, Shigematsu T, Hamano T, Yamagata K, Watanabe Y, et al. An overview of regular dialysis treatment in Japan (as of 31 December 2007). Ther Apher Dial. 2009;13:457-504.

9. Nakai S, Watanabe Y, Masakane I, Wada A, Shoji T, Hasegawa T, et al. Overview of regular dialysis treatment in Japan (as of 31 December 2011). Ther Apher Dial. 2013;17:567-611.

10. Yamagata K, Yagisawa T, Nakai S, Nakayama M, Imai E, Hattori M, et al. Prevalence and incidence of chronic kidney disease stage G5 in Japan. Clin Exp Nephrol. 2015;19:54-64.

11. Hattori M, Sako M, Kaneko T, Ashida A, Matsunaga A, Igarashi T et al. End-stage renal disease in Japanese children: a nationwide survey during 2006-2011. Clin Exp Nephrol. 2015. Jan 17. doi:10.1007/s10157-014-1077-8 [Epub ahead of print].

12. Bureau S. Ministry of Internal Affairs and Communications: current population estimates as of October 1. 2011. http://www.e-stat.go.jp/SG1/ estat/ListE.do?lid=000001088119. Accessed 29 May 2014

13. Statistics Bureau, Ministry of Internal Affairs and Communications: population by age (single year) and sex (as of October 1 of each year) -total population, Japanese population(from 2000 to 2010). http://www.e-stat.go.jp/ SG1/estat/List.do?bid=000001039703\&cycode=0. Accessed 29 May 2014.

14. U.S. Renal Data System, USRDS 2011 annual data report: atlas of CKD and ESRD. http://www.usrds.org/atlas11.aspx. 2011. Accessed 29 May 2014.

15. Noordzij M, Kramer A, Abad Diez JM, Alonso de la Torre R, Arcos Fuster E, Bikbov BT, et al. Renal replacement therapy in Europe: a summary of the 2011 ERA-EDTA registry annual report. Clin Kidney J. 2014;7:227-38.

16. McDonald S CS, Excell L. New patients commencing treatment in 2006 [Chapter 2]. In: ANZDATA Registry Report 2007. Australia and New Zealand Dialysis and Transplant Registry, Adelaide, South Australia. http://www. anzdata.org.au. Accessed 11 Sept 2015

17. McDonald S, Eecell L, Dent H. New patients commencing treatment in 2007 [chapter 2]. In: ANZDATA Registry Report 2008. Australia and New Zealand Dialysis and Transplant Registry, Adelaide, South Australia. http://www. anzdata.org.au. Accessed 11 Sept 2015.

18. ANZDATA Registry. 37th report, chapter 1: incidence of end stage kidney disease. Australia and New Zealand Dialysis and Transplant Registry, Adelaide, Australia. 2015. http://www.anzdata.org.au. Accessed 11 Sept 2015.

19. Yamagata K, Nakai S, Masakane I, Hanafusa N, Iseki K, Tsubakihara Y. Ideal timing and predialysis nephrology care duration for dialysis initiation: from analysis of Japanese dialysis initiation survey. Ther Apher Dial. 2012;16:54-62.

20. AlHW. Assessment of the coding of ESKD in deaths and hospitalisation data: a working paper. Cat. no. PHE 182. Canberra: AlHW; 2014

21. Trehan A, Winterbottom J, Lane B, Foley $R$, Venning $M$, Coward $R$, et al. End-stage renal disease in Indo-Asians in the North-West of England. QJM. 2003;96:499-504.

22. Chandie Shaw PK, Baboe F, van Es LA, van der Vijver JC, van de Ree MA, de Jonge $\mathrm{N}$, et al. South-Asian type 2 diabetic patients have higher incidence and faster progression of renal disease compared with Dutch-European diabetic patients. Diabetes Care. 2006:29:1383-5.

23. van Dam RM, Li T, Spiegelman D, Franco OH, Hu FB. Combined impact of lifestyle factors on mortality: prospective cohort study in US women. BMJ. 2008;337:a1440

24. Wakasugi M, Kazama JJ, Narita I, Iseki K, Moriyama T, Yamagata K, et al. Association between combined lifestyle factors and non-restorative sleep in Japan: a cross-sectional study based on a Japanese health database. PloS One. 2014:9:e108718

25. Coresh J, Selvin E, Stevens LA, Manzi J, Kusek JW, Eggers P, et al. Prevalence of chronic kidney disease in the United States. JAMA. 2007:298:2038-47.

26. Imai E, Horio M, Watanabe $T$, et al. Prevalence of chronic kidney disease in the Japanese general population. Clin Exp Nephrol. 2009:13:621-30.

27. Imai E, Yamagata K, Iseki K, Iso H, Horio M, Mkino H, et al. Kidney disease screening program in Japan: history, outcome, and perspectives. Clin J Am Soc Nephrol. 2007;2:1360-6.

28. Hogg RJ. Screening for CKD in children: a global controversy. Clin J Am Soc Nephrol. 2009:4.509-15.

29. Harambat J, van Stralen KJ, Kim JJ, Tizard EJ. Epidemiology of chronic kidney disease in children. Pediatr Nephrol. 2012:27:363-73. 